\title{
SISTEM INFORMASI PELAYANAN JASA LAUNDRY BERBASIS SMS GATEWAY
}

\author{
Reti Handayani ${ }^{1}$, Fauziah Nur ${ }^{2}$ \\ 1,2 .Manajemen Informatika, AMIK Bukittinggi, \\ Email: jeranikasdun@gmail.com, fauziah11@gmail.com
}

\begin{abstract}
Information System Design Services at KIA Laundry aim to design information programs that are used to provide convenience in the administrative process, especially in the reception and notification when the laundry has been completed, and to share information on packages that are in the laundry using the SMS Gateway system is one of the communications with text via a mobile device. The system development model uses the SDLC System Development Life Cycle Development model, data taken through survey techniques using a list of questions relating to internal control that have been prepared, then proceed with field studies, literature studies and analysis. With the application program in the reception of Laundry is able to facilitate data processing in the field of Administration / Employees quickly and efficiently and can provide information quickly to customers with text messages via SMS gateway
\end{abstract}

Keywords: Information System, SMS gateway, SDLC

\begin{abstract}
Abstrak: Perancangan Sistem Informasi Pelayanan jasa pada KIA Laundry bertujuan untuk merancang program informasi yang digunakan untuk memberikan kemudahan dalam proses administrasi terutama dalam Penerimaan serta pemberitahuan jika laundry sudah selesai dikerjakan, serta untuk membagikan informasi paket yang ada pada laundry dengan memakai sistem SMS Gateway adalah salah satu alat komunikasi yang dikirim kan berupa teks atau pesan singkat yang dikirimkan melalui perangkat berjalan (mobile device). Model pengembangan sistem menggunakan model pengembangan Sistem Development Life Cycle SDLC, data diambil melalui teknik survey dengan menggunakan daftar pertanyaan yang berkaitan dengan pengendalian intern yang telah disiapkan, kemudian dilanjutkan dengan studi lapangan, studi kepustakaan dan analisis. Dengan adanya program aplikasi dalam penerimaan Laundry ini mampu mempermudah Pengolahan data pada bidang Administrasi / Karyawan secara cepat dan efisien dan dapat memberikan info secara cepat kepada pelangan dengan pesan teks melalui SMS yang disebarkan secara bersamaan.
\end{abstract}

Kata Kunci : Sistem Informasi, SMS gateway, SDLC

\section{PENDAHULUAN}

Sistem pendataan pelanggan dan sistem transaksi yang digunakan oleh KIA Laundry Bukittinggi masih menggunakan cara manual tanpa menggunakan komputer untuk mempermudah kegiatan Administrasi yang ada di KIA Laundry. Perkembangan teknologi, teknologi komputer dan teknologi komunikasi pada saat ini telah mengalami banyak perubahan dan kemajuan yang sangat canggih dan pesat. Dan perkembangan teknologi tersebut tidak lepas dari peran manusia yang setiap saat terus memperbaiki dan mencari inovasi baru agar teknologi tersebut dapat digunakan untuk membantu pekerjaan manusia. Salah satu contoh nya adalah SMS gateway Tentunya sekarang sudah banyak teknologi - teknologi yang dapat membantu serta mempermudah pekerjaan manusia dan aktivitas manusia sehari-hari.

Pada kenyataannya, dilihat di lapangan masih ada perusahaan / organisasi atau instansi yang belum menggunakan teknologi komputer dan teknologi internet sebagai alat bantu untuk menyelesaikan suatu kegiatan atau pekerjaan, seperti salah satu sistem jasa cuci di KIA Laundry dimana jasa Laundry ini menyediakan 
Cuci Kiloan / Satuan, Cuci Setrika, Cuci Saja, Setrika Saja, bermacam - macam Selimut, Badcover lengkap, Jas / Blazer, Kebaya, Gorden serta Bermacam - macam tas..

KIA Laundry merupakan salah satu jasa cuci kiloan dan satuan yang sedang dalam tahap pengembangan yang memerlukan suatu sistem yang mendukung untuk kebutuhan operasional, niat dari KIA Laundry untuk menambah cabang terasa sulit jika tidak didukung dengan sistem yang memadai.

Selama ini proses kegiatan administrasi seperti pembukuan, pencatatan data pelanggan laundy dan termasuk pendapatan serta pelayanan masih bersifat manual. Transaksi penerimaan Laundry masih dicatat dalam Nota penerimaan Laundry. Sehingga untuk mencari data mengalami kesulitan dan menghabiskan waktu yang lama. Selain itu pendataan pembelian barang untuk kebutuhan Laundry juga masih menggunakan pendataan manual sehingga untuk mengetahui pengeluaran Laundry membutuhkan waktu yang relatif lama.

\section{Sistem Informasi}

Sistem informasi pelayanan adalah satu jenis aplikasi komputer yang digunakan untuk bisnis yang berkaitan dengan jasa pelayanan, terutama dalam system penyimpanan data hasil pelayanan tersebut dan pengolahan data pelanggan dan keuangan maupun informasi agar dapat menjalani bisnis laundry dengan cepat dan mudah berjalan dengan baik, (Husnil Kamil, 2016)

\section{SMS Gateway}

SMS atau Short Message Service merupakan salah satu cara melaksanakan komunikasi dengan menggirim pesan teks melalui perangkat berjalan atau bergerak (mobile device). SMS juga merupakan salah satu sarana komunikasi yang mudah dipahami dan dimengerti oleh setiap lapisan masyarakat saat ini karena ratarata hampir semua lapisan masyarakat sudah mempunyai media komunikasi handphone (Afrina \& Ibrahim, 2015)

SMS Gateway adalah suatu aplikasi yang memanfaatkan atau menggunakan fasilitas berupa pesan SMS, yang digunakan untuk pengiriman data secara ringkas dan pendek yang memungkinkan seorang pengguna telepon selular mendapatkan informasi dari aplikasi tersebut dan merupakan salah satu cara yang mudah untuk mendapat kan informasi (Isnawati Mulyani, Eri Satria, 2012)

\section{METODOLOGI PENELITIAN}

Dalam penelitian ini, menggunakan metode analisa yang umum dibidang komputer yaitu System Development Life Cycle (SDLC)

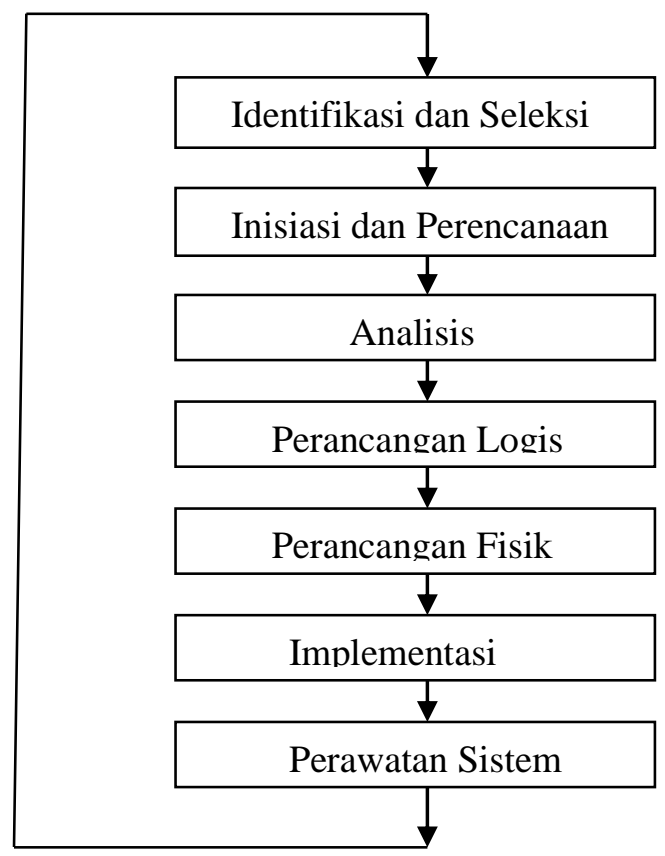

Gambar 1. Metode SDLC

Pada tahap perencanaan adalah suatu kegiatan yang harus dilakukan untuk membangun atau merancang sebuah sistem. Pada tahap perencanaan ini diperlukan analisa kelayakan dengan mencari data atau melakukan proses pengumpulan informasi yang didapat dari pemilik KIA Laundry di Tarok Dipo Bukittinggi dengan wawancara. 


\section{HASIL DAN PEMBAHASAN}

Dari SMS yang dikirim kan oleh operator yang bekerja pada Laundry KIA itu merupakan suatu kegiatan yang akan menggunakan teknologi mengirim, dan menerima, bahkan mengolah pesan sms melalui komputer, dimana SMS yang dikirimkan berupa waktu pemberitahuan tentang laundry sudah siap dan bisa dijemput, atau pun berupa promosipromosi lain yang untuk para pelanggan balik lagi menggunkan jasa laundry KIA.

SMS merupakan salah satu fitur aplikasi pada setiap handphone dengan kata lain semua jenis handphone mempunyai fitur atau aplikasi SMS dan sudah merupakan fitur bawaan dari handphone tersebut, yang pasti sangat mudah digunakan oleh para user, baik untuk menerima atau pun mengirim SMS.

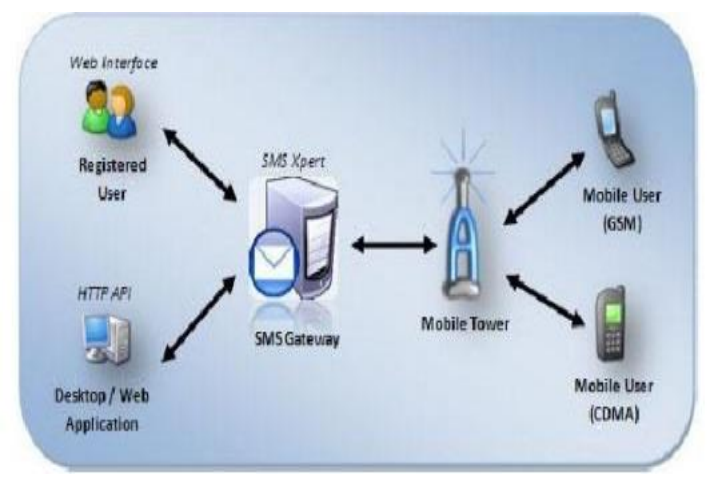

Gambar 2. Skema SMS Gateway

Mekanisme kerja pengiriman SMS yaitu, dari Operator yaitu dari Jasa Laundry KIA. (yang akan mengirim kan SMS), selanjutnya Inter Operator yaitu pengririman operator antar opearator yang berbeda, karna dari pelanggan Laundry KIA tidak memakai satu jenis opearator saja dan beragam provider lainnya, karena pelanggan dari KIA Laundry rata-rata sekarang masih penduduk setempat maka belum digunakan operator antar negara. Jadi mekanisme atau alur kerja SMS Gateway dari awal pengiriman pesan sampai ke pelanggan laundry dapat di lihat pada gambar.

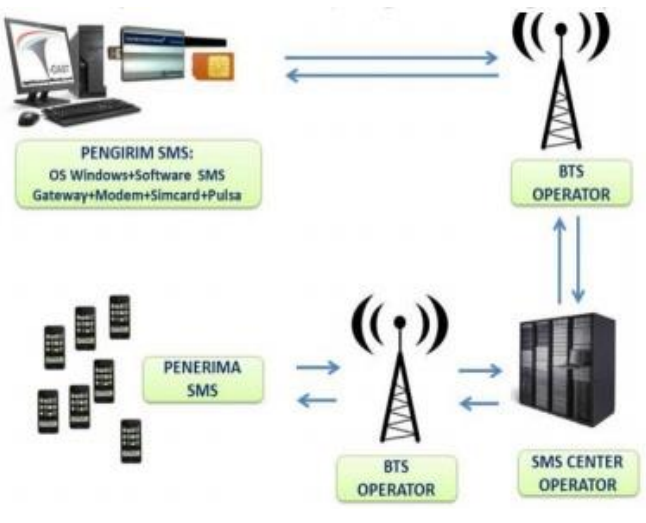

Gambar 3. Cara Kerja SMS Gateway

\section{Perancangan Sistem Informasi}

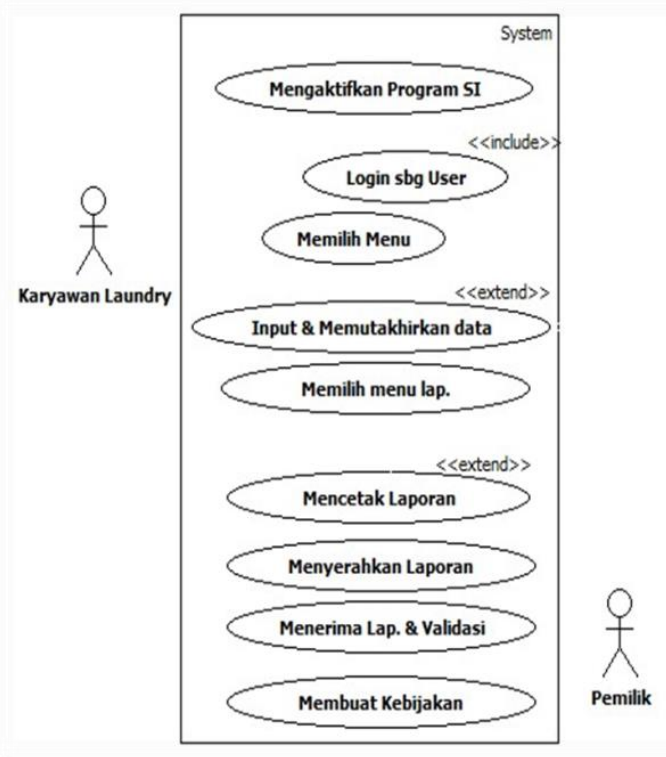

Gambar 4. Usecase Diagram

Use Case Diagram ini merupakan model atau diagram yang digunakan untuk menggambarkan interaksi aktor utama setelah dilakukan perancangan Sistem . Adapun Sistem baru yang dirancang adalah dengan membangun sebuah modul program aplikasi komputer untuk membantu kerja Karyawan Laundry. Dengan demikian Karyawan Laundry yang sebelumnya merupakan aktor pendukung, telah menjadi aktor utama pengguna modul program dan menjadi operator untuk mengirimkan pesan ke pelanggan melau SMS. Yang mana dalam satu pengiriman sudah diterima oleh banyak pelanggan. 
Activity Diagram merupakan alat pemodelan grafis yang dapat digunakan untuk mengambarkan kegiatan yang dilakukan aktor terhadap sistem, maupun sistem itu sendiri dan juga menggambarkan kerja modul program aplikasi yang dirancang.

\section{a. Aktivity Diagram Aktor Utama}

\section{Pelanggan}

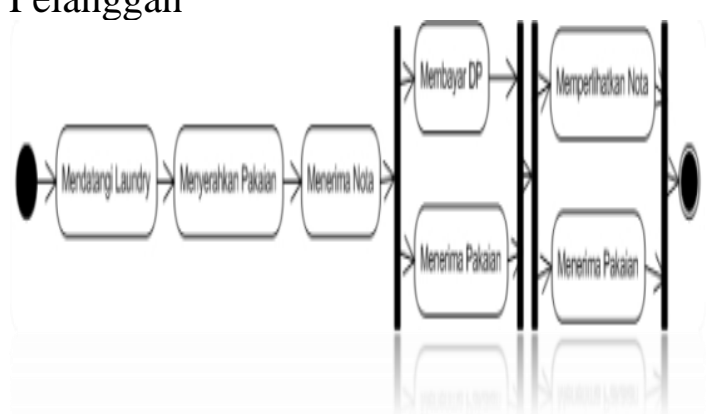

Gambar 5. Aktivity Diagram

b. Aktivity Diagram Aktor Utama Pemilik

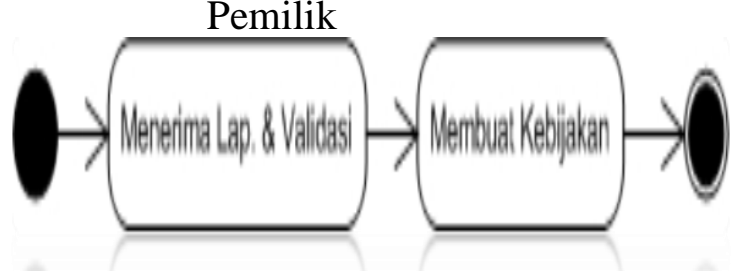

\section{Gambar 6. Aktivity Diagram Pemilik}

Class diagram yang dirancang pada KIA Laundry akan menggambarkan bagaimana perancangan sistem untuk KIA Laundry. Semua proses yang akan dilakukan oleh aktor atau yang disini berperan adalah pegawai bagian administrasi yang ditunjuk untuk menjalankan sistem maka dirancangkan melalui class diagram yang didefinisikan dengan menggambarkan class diagram. Class diagram menunjukan bentuk visualisasi dalam pembuatan sistem. Masing-masing class memiliki atribut dan fungsi dengan proses proses yang terjadi. Adapun bentuk class diagram dari Sistem Informasi Pelayanan Jasa pada KIA Laundry dapat dilihat sebagai berikut:

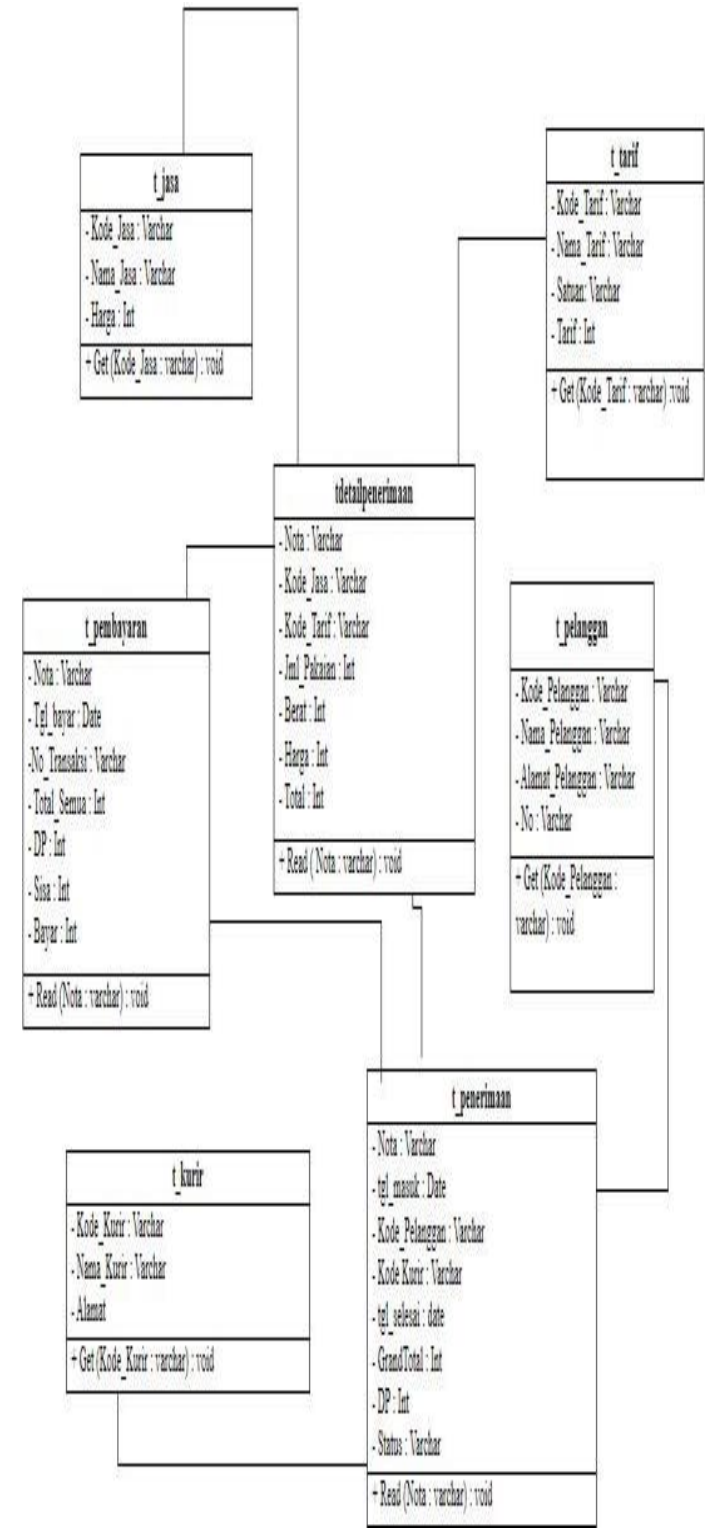

Gambar 7. Class Diagram

Sequence Diagram merupaka gambaran dari kerja Sistem yang dirancang pada KIA Laundry dan akan menampilkan cara kerja atau pun hubungan dari beberapa yang terlibat dalam sistem 


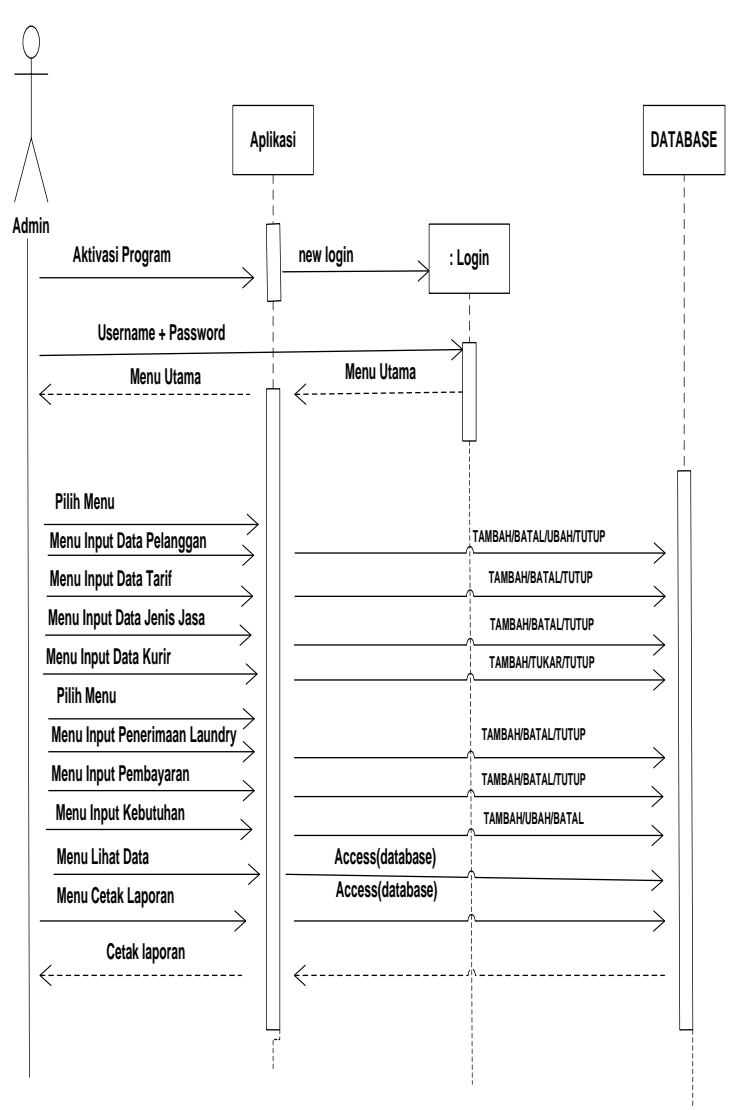

\section{Gambar 8. Sequence Diagram}

Dari hasil perancangan Sistem maka didapat kan suatu output atau media interface operator pada KIA Laundry

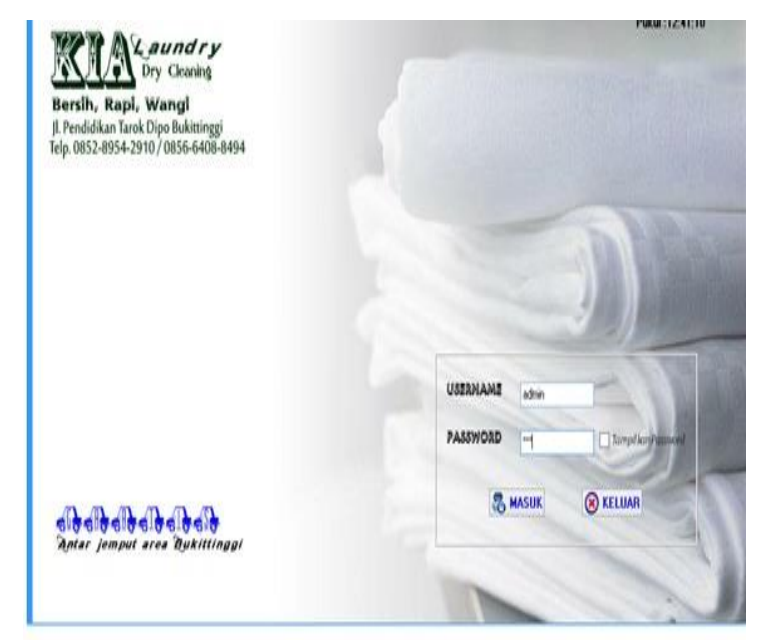

Gambar 9. Menu Utama Pada KIA

\section{KESIMPULAN}

Sistem Informasi Pelayanan Jasa pada KIA Laundry hendak nya dapat memberikan sebuah terobosan dalam hal pemangkasan waktu dalam pengelolaan informasi dan transaksi pada pelanggan laundry dengan mengutamakan pelayanan jasa kepada para pelanggan serta dengan cepat bisa memberikan informasi kepada pelanggan jika cucian pelanggan yang sudah siap bisa dijemput atau memberikan informasi lainnya tentang KIA Laundry melalui SMS Gateway jika ada nya promosi atau bonus pada pelanggan KIA Laundry yang no Handphone nya sudah terdaftar di KIA Laundry.

\section{Daftar Pustaka}

Afrina, M., \& Ibrahim, A. (2015). Pengembangan Sistem Informasi SMS Gateway Dalam Meningkatkan Layanan Komunikasi Sekitar Akademika Fakultas Ilmu Komputer Unsri. Jurnal Sistem Informasi, 7(2), 852-864.

Husnil Kamil, A. D. (2016). Pembangunan Sistem Informasi Pelayanan Jasa Laundry Berbasis Web Dengan Fitur Mobile Pada 21 Laundry Padang. Seminar Nasional Sains Dan Teknologi Fakultas Teknik Universitas Muhammadiyah Jakarta, 8(November), 1-9. Retrieved from https://media.neliti.com/media/public ations/172316-ID-pembangunansistem-informasi-pelayanan-j.pdf

Isnawati Mulyani, Eri Satria, A. D. S. (2012). Pengembangan Short Message Service (SMS ) Gateway. Jurnal STT Garut, 09(11), 1-9. 